\title{
The impact of the great recession on employment polarization in Spain
}

\author{
Brindusa Anghel · Sara De la Rica • \\ Aitor Lacuesta
}

Received: 31 May 2013 / Accepted: 24 February 2014 / Published online: 25 March 2014 (C) The Author(s) 2014. This article is published with open access at SpringerLink.com

\begin{abstract}
This article analyzes changes in the occupational employment share in Spain for the period 1997-2012 and the way particular sociodemographic groups adapt to those changes. There seems to be clear evidence of employment polarization between 1997 and 2012 that accelerates over the recession. Changes in the composition of the labour supply cannot explain the increase in the share of occupations at the low end of the wage distribution. Sector reallocation may have partially contributed to explain the polarization process in Spain during the years of expansion (1997-2007) but it is a minor factor during the recession. The polarization of occupations within sectors observed, especially during the recession, appears to be related to a decline in routine tasks which is compensated by an increase in occupations with non-routine service contents, which are found both in the low and high end of the wage distribution. Instead, jobs with a higher degree of abstract contents do not appear to increase their share in total employment during these 15 years. The paper finds that this process has affected males more strongly than females because of their higher concentration in
\end{abstract}

\footnotetext{
Authors are grateful to Juan Francisco Jimeno and to two anonymous referees for their comments and suggestions. We also gratefully acknowledge the support from the Ministry of Science and Technology through grants ECO2012-31985 and ECO2012-35820.
}

B. Anghel · S. De la Rica

FEDEA, Madrid, Spain

e-mail: banghel@fedea.es

S. De la Rica $(\varangle)$

UPV/EHU, Bilbao, Spain

e-mail: sara.delarica@ehu.es

A. Lacuesta

Bank of Spain, Madrid, Spain

e-mail: aitor.lacuesta@bde.es 
occupations more focused on routine tasks. Among males, for workers under 30 years old, we find a decrease in the share of occupations with more routine tasks which turns into increases in those with more abstract content and particularly with more non-routine service content. Instead, male workers over 30 years old seem to remain in declining occupations to a greater extent. Females of different ages are not affected by the abovementioned changes.

Keywords Employment polarization $\cdot$ Job tasks $\cdot$ Routinization $\cdot$ Business cycle

JEL Classification $\quad$ E24 $\cdot \mathrm{J} 24 \cdot \mathrm{J} 62 \cdot \mathrm{O} 33$

\section{Introduction}

Structural unemployment depends on a broad set of factors among which there are some institutional considerations which have to do with labour market regulation, product market regulation and the mismatch between occupations demanded by the market and the ability of different skill groups. This article analyzes the evolution of occupations in Spain for the period 1997-2012 identifying the structural part of this change. Moreover, it tests several hypotheses regarding the underlying factors of this structural change and the way particular sociodemographic groups adapt to it.

This question is relevant because one might want to use the observed changes in occupations over time to shed some light on the evolution of the demand for labour in the near future. However, it is not clear at first sight to what extent those changes arise as a result of structural variation in the demand for labour or as a result of other forces. On the one hand, one must take into account that the Spanish labour force has undergone a notable structural change over the last cycle. Indeed, there has been a substantial increase in the schooling attainment of the population, in female participation and in the supply of low-skilled immigrants which has affected the supply skill composition in the economy. On the other hand, the employment share of the Construction Sector changed enormously throughout the cycle. Total employment in that sector increased around $5 \mathrm{pp}$ between 1994 and 2007 (from 8.7 to $13 \%$ ) and decreased by $7 \mathrm{pp}$ from 2007 onwards (reaching 6\% of total employment by the first term of 2013-a level more in accordance with the share of this sector in other European economies). Since the beginning of the actual recession and as a consequence of the construction bust, this sector contributed to almost half of the 3.8 million jobs destroyed, and it is certainly not expected that in the future it will recover the same level of activity as in the recent past. The paper explores these issues in detail.

Recent evidence from a variety of countries has found a neat decline in the share of middle wage occupations which has been named the polarization process. Indeed, some authors, such as Autor and Dorn (2013) find that this process has accelerated during the great recession. This reallocation of workers has been mainly observed within different industries and this has led many scholars to relate this phenomenon to a change in technology motivated by a decrease in the price of capital goods. Indeed, Autor et al. (2003) and Goos et al. (2009) relate the abovementioned polarization process to a decrease in the demand for occupations performing routine job contents 
or tasks that workers in the middle-wage occupations perform and which can be easily mechanized. On the other hand, it has also been documented that occupations which perform jobs that are more difficult to be substituted by technology, such as abstract qualified occupations or unqualified jobs which require interpersonal skills, are rising in relative employment terms. This means that workers previously performing routine tasks have been reallocated to jobs requiring either more abstract or more interpersonal service job contents or tasks.

There is a growing literature that finds that allocation of skills into tasks might play an important role in explaining the difference in growth between the USA and Europe (Wasmer 2006), the higher unemployment rate in Europe than in the USA (Ljungqvist and Sargent 1998), the recent growth in wage inequality (Gavilán 2012; Autor et al. 2003) and jobless recoveries (Jamovich and Siu 2012). Although Goos et al. (2009) provide evidence of polarization for many European countries, including Spain, this paper is the first one to address, in detail, the polarization hypothesis for Spain at different moments of the business cycle as well as its different impact on different sociodemographic groups of workers.

To this end, the paper analyzes labour market changes over the last complete cycle (expansion and recession) to provide evidence of structural changes of the Spanish economy which might shape the way forward for its labour market. Indeed, since 1994, Spain has had 13 years of economic growth and 5 years of recession. By comparing changes from the starting to the end point of a whole economic cycle, we can distinguish structural movements from more cyclical ones. The paper focuses on labour market changes over the period 1997-2012 (ten years of expansion and five years of recession) instead of 1994-2012, which would delimit the whole business cycle better because it is only since 1997 that we have access to 3-digit level data on occupations in our database, which is highly recommended in order to perform the matching of tasks to occupations. As a consequence, we lose 3 years but that period is fairly similar to the period 1997-2012 in terms of labour force and employment composition.

Section 2 describes the important changes in the occupational distribution which Spain went through during these years. Whereas in the upper part of the wage distribution, the share of managers, professionals and technicians increased, in the lower part, the share of retail sales and services occupations and low-skilled occupations related to the service sector also increased. Instead, those jobs related to construction, agriculture or industry, regardless of their qualifications, declined in terms of relative employment. Interestingly, the increases even in the high end of the wage distribution are related to service tasks more than to abstract ones. All these changes over the cycle are documented in the second section of the paper.

Section 3 is devoted to confirm empirically that Spain also went through a polarization process over the 15 year interval. Potential changes in this process between the expansion and the recession period are accounted for. In addition, this section explores different hypotheses behind the polarization process such as changes in the labour supply, changes in the sectoral structure and changes in technology within sectors. It is found that neither of the first two hypotheses can explain the whole polarization process, whereas the latter one seems to fit the process better. To test for the latter, we distinguish between the already mentioned "routine tasks" from "abstract tasks" (job contents which require active learning, management of personal resources, deduc- 
tive reasoning, speech clarity, or complex problem solving) and "Non-Routine Service tasks" (which entails activities that require caring for others, establishing and maintaining interpersonal relationships, selling and influencing others and active listening). In the United States, polarization has been driven by a growth in abstract tasks-usually at the upper part of the wage distribution, and low-skilled services-usually at the lower end of the wage distribution, coupled with a decrease in occupations with a high degree of routine tasks which lie around the middle of the wage distribution. However, it might not be possible to extrapolate this pattern to other countries, so we look at the connection between the polarization process and changes in the occupational distribution driven by changes in the tasks performed by workers in Spain.

Finally, Sect. 4 explores how changes in the demand for tasks over time cause different effects on different sociodemographic groups. Males and females at different stages of their life cycle are somehow segregated into different types of occupations and their ability to reallocate might differ because of their different capacity to readapt their accumulated human capital over time. Indeed, for the US, Autor and Dorn (2009) found that those in occupations more related to routine jobs have aged in the US, whereas workers in jobs which are closely related to abstract and service jobs have become younger.

\section{Changes in the distribution of employment}

During the last 15 years, employment growth in the private sector has been heterogeneously distributed among occupations. Figure 1 presents changes in the employment shares of seven major occupational groups for the private sector (including selfemployed). Occupations are ranked according to average 1995 wages, from highest to lowest. The figure reveals that between 1997 and 2012 there were three broad occupational groups which expanded their share in private sector employment. These are, according to the expansion magnitude, managers, professionals and technicians, whose expansion reached 7.8 percentage points (henceforth $\mathrm{pp}$ ); retail sales and service occupations, whose employment share increased in $3.91 \mathrm{pp}$ and finally, low-skilled service occupations, with an almost negligible increase of $0.07 \mathrm{pp}$. The rest of the occupations declined in terms of relative employment. The occupational groups which declined most are production and craft occupations $5.9 \mathrm{pp}$, qualified workers in agriculture, which experienced a decrease of $3.7 \mathrm{pp}$, and machine operators and assemblers, with a decrease in $2.1 \mathrm{pp}$. Finally, clerical and civil servants declined very slightly, $0.09 \mathrm{pp}$.

Notice that the expanding occupations are precisely those whose contents have much to do with either abstract or service tasks. Indeed service tasks appear to be very related to the increase in the share of expanding occupations. More than half of the increase in managers, professionals and technicians is associated with increases in the share of administrative and business associate professionals; physicists, chemists and engineer professionals and technicians; and salespersons and restaurant service workers who are managers of their own business. The big increase in retail sales and service occupations is associated with an increase in personal services and the increase in low-skilled services is associated with an increase in domestic service occupations. 


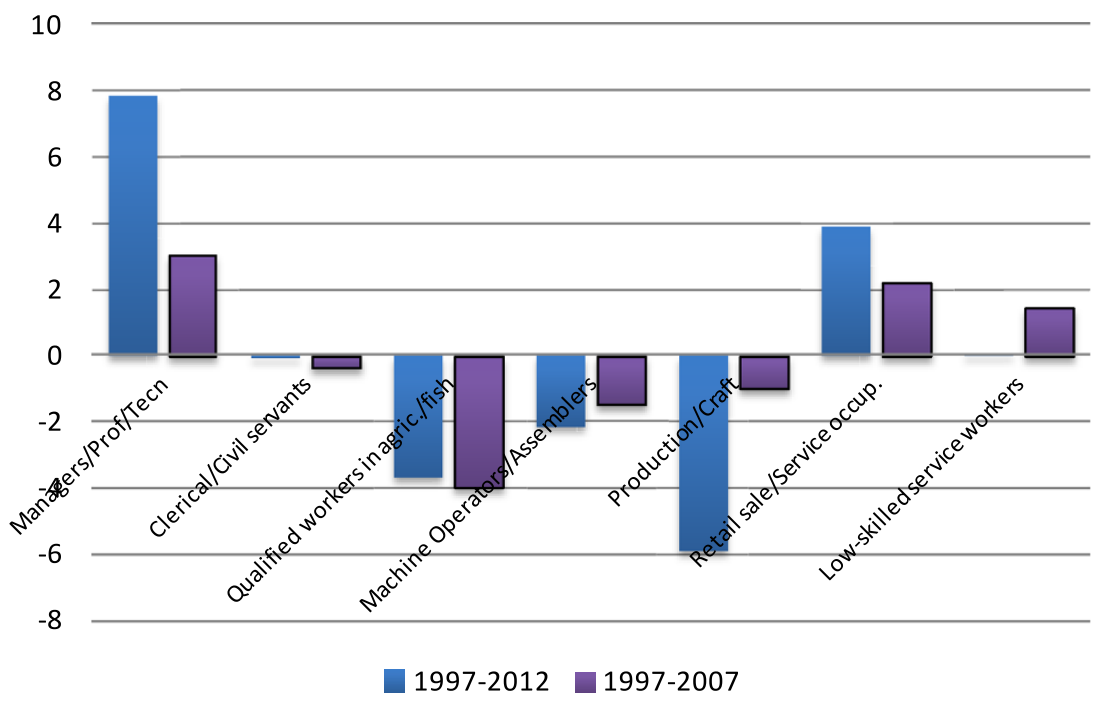

Fig. 1 Changes in the share of private sector employment by occupation

Rather, the declining occupations seem to be much more associated with routine tasks. This will be further explored in Sect. 3 .

It is also remarkable that expanding and declining occupations in the overall period remain as such when only the expansionary period (1997-2007) is taken into account. This provides an idea of the structural character of the employment composition changes across occupations in the Spanish economy regardless of the sizable housing boom that the Spanish economy experimented with during the expansionary period. From the comparison between the whole period and only the expansionary one, it looks like during the recession years (2007-2012), occupations related to managers, professionals and technicians expanded much more than those related to non-qualified services. Indeed, there is an important increase in the share of service sector managers between 2007 and 2012.

Given that gender segregation across occupations is high in Spain, it is interesting to present changes in the structure of employment by occupation separately for men and women. Again, this distinction might shed light on the structural character of the occupational changes since females were not affected as much by the housing boom and bust as males. Table 1 provides a static picture of the gender segregation of employment in 1997, the starting period of analysis. The evidence of the occupational segregation by gender is really high-males are much more concentrated in occupations related to machine operators, assemblers, craft and production whereas female jobs are basically associated with services of different types. The second interesting feature is that by 1997 males were overrepresented in declining occupations with respect to females.

Figures 2 and 3 represent the change in the distribution of occupations by gender over the whole 15-year period, as well as only for the expansionary period. As for males, Fig. 2 reveals that over the 15-year interval the share of male employment 
Table 1 Share of private sector employment by occupation 1997

\begin{tabular}{|c|c|c|c|c|c|c|c|c|}
\hline \multirow[t]{2}{*}{ Occupational groups } & \multirow[t]{2}{*}{ Average wage } & \multirow[t]{2}{*}{ Overall } & \multicolumn{2}{|l|}{$16-30$} & \multicolumn{2}{|l|}{$31-45$} & \multicolumn{2}{|l|}{$46-64$} \\
\hline & & & Males & Females & Males & Females & Males & Females \\
\hline Managers/prof/tecn & 26.450 & 24.88 & 16.4 & 22.21 & 27.58 & 29.74 & 27.03 & 27.62 \\
\hline Clerical/civil servants & 13.895 & 9.09 & 6.4 & 20.47 & 6.77 & 14.28 & 5.36 & 6.88 \\
\hline Qualified workers in agric./fish & & 6.54 & 4.06 & 1.46 & 6.32 & 3.44 & 11.82 & 12.85 \\
\hline Machine operators/assemblers & 13.418 & 11.8 & 13.91 & 6.03 & 15.37 & 6.08 & 14.98 & 4.22 \\
\hline Production/craft & 12.945 & 19.64 & 26.84 & 4.06 & 27.68 & 4.13 & 26.98 & 4.26 \\
\hline Retail sale/service occup. & 11.079 & 13.3 & 13.02 & 29.54 & 8.09 & 20.02 & 4.69 & 17.66 \\
\hline Low-skilled service workers & 9.049 & 14.76 & 19.36 & 16.23 & 8.2 & 22.3 & 9.15 & 26.51 \\
\hline
\end{tabular}

Source Spanish Labour Force Survey (LFS) and Wage Structure Survey (WSS) 1995

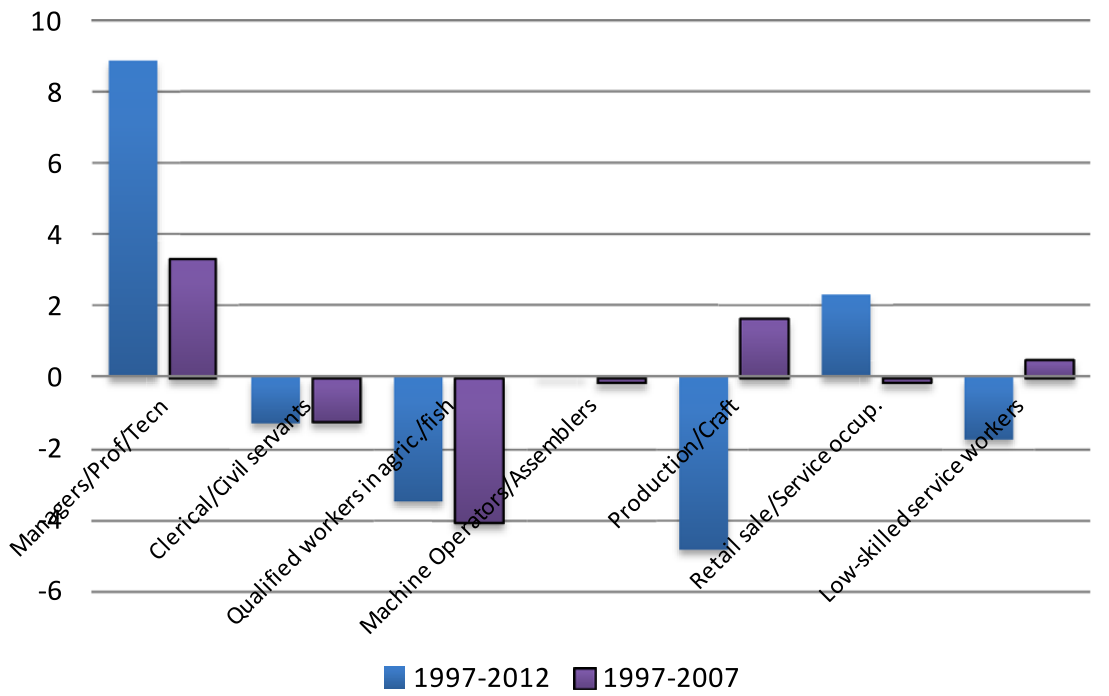

Fig. 2 Changes in the share of private sector employment by occupation-males

increases to a greater extent in occupations related to managerial, technical and professional jobs; also, although to a lesser extent, in those related to sale and service occupations and finally, the increase is almost negligible in occupations related to machine operators and assemblers. On the contrary, male occupational shares decline sizably in production and craft (occupations related to the construction sector), qualified occupations in agriculture; and to a lesser extent, in clerical and civil servant jobs and low-skilled service workers (also related to the construction sector). If we focus only on the expansionary period, the most remarkable difference concerns the share of males working in occupations related to construction (production and craft and low-skilled primarily). Contrary to the overall period, where the share of those two major occupation groups decreased, during the expansion, they experienced a strong increase. Changes in the share of employment across the rest of the occupations do not differ much between the two year intervals. 


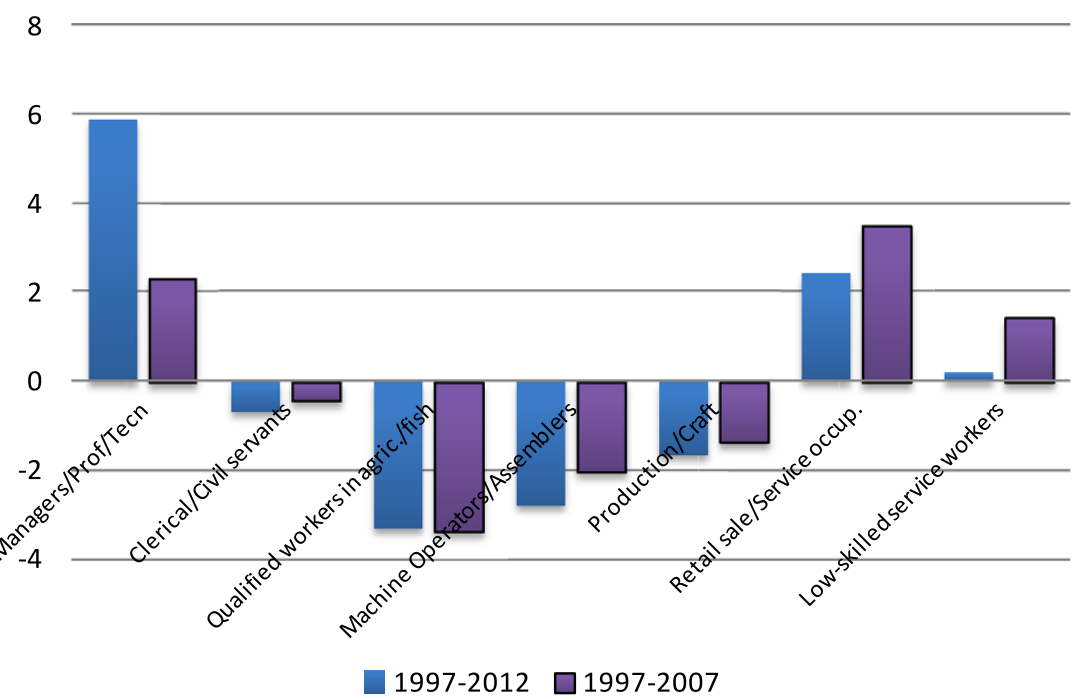

Fig. 3 Changes in the share of private sector employment by occupation-females

With regards to women, changes observed for the overall period and for the expansionary period are very much the same with important increases in occupations related to managerial, professional and technical jobs and retail sales. This is very much related to the enormous entrance of women into employment from inactivity during the recession as a result of the "added worker" effect. Many of these women are directed into jobs related to sales and services either as managers or as employees. With regards to other occupations, the share of female employment decreases in manual occupations, such as production and craft and machine operators and assemblers and increases slightly in low service occupations.

To summarize, for both males and females and for the overall 15-year period, we observe increasing shares of employment in managerial, technical and professional jobs as well as retail sales and services occupations. On the other hand, we observe decreasing shares in manual occupations. In the following two sections, we analyze, with a higher degree of disaggregation, whether the above mentioned changes in occupations could be understood in a polarization framework. We also analyze different hypotheses behind this process at different moments of the cycle and how different sociodemographic groups adapt to these changes.

\section{Polarization and the observed changes in employment shares}

\subsection{Is there evidence of employment polarization in Spain?}

Following Goos and Manning (2007) and Autor et al. (2006), we present some figures relating changes in the share of employment to the ranking of occupations in terms of average wages in Spain. We do so first for the entire period: 1997-2012 and then only for the expansionary period-1997-2007. 

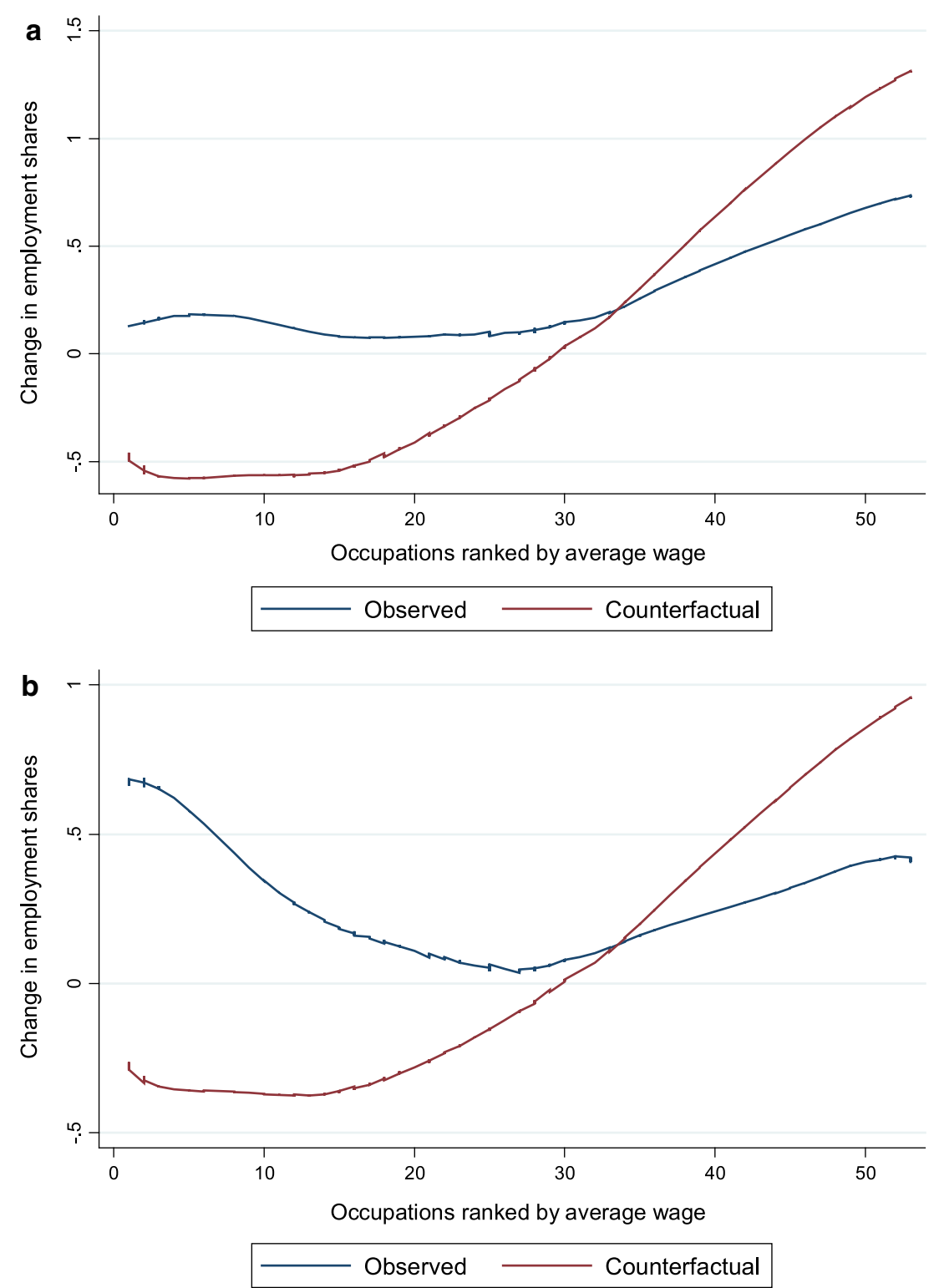

Fig. 4 a Smoothed change in employment shares by occupations (1997-2012). b Smoothed change in employment shares by occupations (1997-2007)

Figure $4 \mathrm{a}, \mathrm{b}$ depict changes in the occupational share of employment following the National Classification of Occupations (1994-CNO-94) at a 2-digit level. Occupations are ranked according to average wages at the beginning of the period. The ranking of wages is obtained from the 1995 Wage Structure Survey (Encuesta de Estructura 
Salarial (EES)), which is the closest one to 1997 , our initial period. ${ }^{1}$ Unfortunately, this evidence must be presented at a 2-digit level occupational disaggregation and not at a higher one given that this is the maximum occupation disaggregation that is available from the different EES waves. The series titled "Observed" present changes in the share for the whole 15-year interval as well as only for the 1997-2007 expansionary period.

There seems to be clear evidence of polarization, both for the expansionary and for the overall 15-year interval. Nevertheless, the expansionary period presents a somewhat different pattern of polarization than the whole 15-year period. In particular, during the first 11 years and coinciding with the expansionary period, low-paying occupations expanded their employment shares relative to average-paying occupations but also with respect to high-paying occupations. These patterns are consistent with the occupational changes described in the previous section. During the expansionary period, high-paid jobs such as professionals and managers increased their share slightly, but the increase in the share was the strongest for the lowest-paid occupations, basically those related to low-skilled services. At least partially, this might reflect the effect of the housing boom in the demand for low skill jobs. Taking the whole 15-year period, high-paid jobs such as high-skilled services related to trade and sales and professionals and managers expand at a slightly higher pace than low-paid occupations such as low-skilled services or clerical jobs. This is overwhelmingly related to the increase in the share of managers of small businesses related to hotels, restaurants, retail and the service sector in general. Indeed, the increase in low-skilled service workers is marginal probably due to the effect of the housing bust on low-skilled services. The group of retail sale and service occupations is the only one whose share increases among those occupations which lay at the low end of the wage distribution. Rather, the increase is much stronger at the upper end.

\subsection{Alternative explanations of the observed job polarization}

\subsubsection{Is job polarization explained by changes in labour supply?}

One potential explanation for the observed job polarization is that it is driven by changes in the composition of the labour supply. The substantial increase in the schooling attainment of the population, the increase in female participation and the increase in the labour supply of low-skilled immigrants may have shaped the supply of skills, increasing it particularly at both ends of the wage distribution and eventually driving a polarization process over the business cycle. Additionally, we know that throughout the crisis, highly educated workers have performed better than low-skilled workers due to, among other things, the different incidence of temporary contracts in each of

\footnotetext{
1 When considering the whole cycle (between 1994 and 2012), the increase in aggregate unemployment is lower. During these years, the decrease in the inactive population ( $6.9 \mathrm{pp})$ was mainly absorbed by increases in employment (5.1 pp) and unemployment as a share of total population only grew by $1.8 \mathrm{pp}$. However, its concentration on particular sociodemographic groups is the same as in the period 1997-2012.
} 
the groups. This factor might have biased the polarization process to the high end of the wage distribution during the recession.

Changes in the labour market activity during this 15 -year interval are impressive. To give some examples, the number of active workers increased by 5.8 million-an average annual increase of $1.1 \%$ - and the number of employed workers by 3.9 millionan average annual increase of $2 \%$. Furthermore, and as it has been documented by other studies (Izquierdo and Lacuesta 2012; Carrasco et al. 2012), these important employment changes have been unevenly distributed across particular groups of the population.

To test whether the observed changes in the labour composition may explain the observed job polarization, we split the working population into 22 cells (gender (2 groups), educational attainment (3 groups), age groups for natives (3 groups), and 4 groups of immigrants depending on their gender and whether they belong to OECD countries or not). We construct counterfactuals of the distribution of occupations (at a 2 digit level) in 2007 and 2012 keeping the 1997 structure of occupations constant within each cell and changing the relative weight of each cell.

The series titled "Counterfactual" in Fig. 4a, b show that changes in the composition of the labour force would have increased the share of occupations placed at the upper end of the wage distribution instead of the polarization process described above. During the recession, compositional changes, if anything, might have contributed even more to the expansion of occupations at the upper part of the wage distribution. Therefore, supply side changes cannot explain the increase in the share of occupations at the low end of the wage distribution and hence we require additional explanations to understand the observed polarization process.

\subsubsection{Is job polarization explained by changes in the sectoral structure?}

The Spanish economy has undergone a notable structural change over the last cycle. Indeed, the incidence of the Construction Sector in total employment increased around 5 pp between 1994 and 2007 (from 8.7 to 13\%) and decreased by 7 pp from 2007 onwards (reaching $6 \%$ of total employment by 2013-Q1, a level more in accordance with the relative incidence of this sector in other European economies). Since the beginning of the actual recession and as a consequence of the construction bust, this sector contributed to almost half of the destruction of 3.8 million jobs. Therefore, it is likely that sector reallocation during the expansion affected the demand of certain occupations and hence changed their share in total employment. To test for this, we can decompose the observed changes in occupation shares into those which could be explained by changes in the sectoral structure of the Spanish economy (changes between sectors) and those changes which occurred within each of the sectors. Table 2 presents a shift share analysis for broader occupation groups ranked by average wages (as in Goos et al. 2009). Employment share changes across sectors can be attributed to demand changes, whereas those within sectors should be more as a result of technology changes. For each of the two periods, the first column shows the change (in pp) in the share of each occupational group. The second column reflects changes between industries and the third one changes within industries. When we consider the whole 15 -year interval, changes within industries are the most important ones right after the 
Table 2 Decomposition of the changes in the share of private sector employment by occupation

\begin{tabular}{|c|c|c|c|c|c|c|}
\hline & \multicolumn{3}{|l|}{ 1997-2012 } & \multicolumn{3}{|l|}{ 1997-2007 } \\
\hline & Change ocup & Within & Between & Change ocup & Within & Between \\
\hline Managers/prof/assoc & 7.43 & 6.21 & 1.22 & 2.82 & 1.01 & 1.81 \\
\hline Clerical/civil servants & 0.06 & -0.26 & 0.32 & -0.26 & -0.47 & 0.21 \\
\hline Qualified workers in agric./fish & -3.80 & -0.88 & -2.91 & -4.03 & -1.01 & -3.02 \\
\hline Machine operators/assemblers & -2.21 & -0.09 & -2.13 & -1.64 & -0.13 & -1.51 \\
\hline Production/craft & -6.19 & -8.74 & 2.55 & -1.25 & -1.32 & 0.08 \\
\hline Retail sale/service occup. & 4.58 & 5.30 & -0.72 & 2.62 & 0.99 & 1.63 \\
\hline Low-skilled service workers & 0.13 & -1.54 & 1.67 & 1.74 & 0.94 & 0.80 \\
\hline
\end{tabular}

The first column corresponds to the average wage of each major occupation in WSS 1995. The rest of the table uses LFS. By sub period the first column corresponds to the change in the share of private sector employment by occupation, the second and the third are computed using a shift share analysis (Goos and Manning 2007)

observed changes in the distribution of occupations. Changes within sectors expanded the employment share of low-paying occupations and high-paying occupations relative to average-paying occupations. The reallocation of workers from craft and production occupations towards managers, professionals and technicians and sales and retail is crucial. On the other hand, during the expansionary period, changes between industries dominate both ends of the wage distribution. By broader occupational groups, those changes across sectors during the expansionary period expanded the employment share of low-paying occupations and high-paying occupations relative to averagepaying occupations. Changes within sectors during this period point towards the same direction of the above mentioned changes between sectors but their importance is minor.

Overall, as opposed to evidence from other countries (Goos and Manning 2007), it appears that changes across sectors, potentially due to the housing boom, might have partially contributed to explain the polarization process in Spain especially during the period of expansion (1997-2007). Nevertheless, when considering the whole cycle (1997-2012), sector reallocation is less important in explaining the polarization process in Spain. We need an alternative explanation that could help us understand the polarization process from the point of view of technological changes within industries, especially for the crisis.

\subsubsection{Is job polarization explained by the routinization process?}

Autor et al. (2003) and more recently Acemoglu and Autor (2011) generalize the so-called canonical model for the labour market which includes two-skill groups of workers (high and low) who work in imperfectly substitutable occupations. Technology takes a factor-augmenting form, and thus may complement either high or low skill workers. Skill biased technical change is captured by changes in the factoraugmenting technology. The canonical model has proved to be conceptually tractable and empirically quite successful. However, it does not include a meaningful role 
for "tasks", or more precisely, impose a one-to-one mapping between skills and tasks.

Acemoglu and Autor (2011) distinguish very clearly the concept of task from that of skill. The latter is a worker's endowment of capabilities to perform different tasks, whereas a unit of task is a unit of work activity which produces output. This distinction is essential if we believe that workers of a given skill level can perform different tasks and furthermore, can change the combination of tasks they perform in response to changes in labour market conditions and technology. These authors develop a task assignment model where it is assumed that there is a continuum of tasks which together produce a final good.

Intuitively, each worker is endowed with either one of the following three types of skills-high, medium or low. Differences in comparative advantage among workers to perform different tasks together with the market prices of different tasks as well as wages for different skills, lead workers to endogenously decide the optimal allocation of skills to tasks. And in equilibrium, Acemoglu and Autor (2011) formally derive that the least complex set of tasks are supplied by the low-skilled workers, the intermediate set of tasks by the medium-skilled workers and finally the most complex tasks will be provided by the high-skilled workers.

One of the most attractive features of this model is that it can be used to investigate the implications of technological changes on worker displacement from previously performed tasks. In particular, routine tasks, which are mostly performed by medium-skilled workers, are those most subject to machine displacement, and therefore task-replacing technological changes can directly reduce wages of the mediumskilled group independent of changes in total output. As these workers lose comparative advantage in routine-intensive activities, they must be reallocated either to the highest or the lowest tails of the occupational distribution, leading to employment polarization.

Testing this theory requires matching occupations with particular job content measures. To this end, two American databases have been used in the literature: The version of the ONET database we use contains 96 variables which reveal the intensity of particular job contents. From these variables, Peri and Sparber (2009), Goos et al. (2010) and Amuedo and De la Rica (2011), make the next aggregation (by either computing the average or a principal component exercise) into abstract, routine and service contents and then match these tasks to 2 or 3-digit occupations. Instead of using the ONET database, one could use the DOT database as in Autor and Dorn (2013). As Autor (2013) argues, with either data sources, job content measures are often vague and are constructed using scales which may confuse respondents. DOT was first issued in 1939 and last revised in 1991. At the time of the last revision, DOT contained 44 objective and subjective job content measures. By 1998, DOT was replaced by ONET, which has been revised several times since then and the number of job content measures has increased substantially. With so many job content measures, researchers who need to use either of these databases must pick and choose among a large number of job content measures. We have decided to use the ONET dataset because it is a more recent one, it has been used to test for routinization in Europe 
Table 3 Intensity of different tasks by broad occupational categories

\begin{tabular}{llll}
\hline Occupational groups & Abstract intensity & Routine intensity & Service intensity \\
\hline Managers/prof/tecn & 0.39 & 0.26 & 0.35 \\
Clerical/civil servants & 0.28 & 0.33 & 0.38 \\
Retail sale/service occup. & 0.24 & 0.38 & 0.38 \\
Qualified workers in agric./fish & 0.30 & 0.49 & 0.21 \\
Production/craft, non-constr. & 0.27 & 0.57 & 0.16 \\
Machine operators/assemblers & 0.26 & 0.51 & 0.24 \\
Low-skilled service workers & 0.17 & 0.58 & 0.25 \\
\hline
\end{tabular}

The intensities of the three tasks for each occupation sum up to one. They are relative task intensities

(by Goos et al. 2010), ${ }^{2}$ and in our view it is better suited to explicitly account for the degree of non-routine service content of each occupation. ${ }^{3}$ The detailed description of the match between occupations and job contents can be found in the "Appendix".

Table 3 presents the abovementioned job contents for the 7 broad occupational groups used in Sect. 2, and as one might expect, high-skilled occupations, such as managers, professionals have the highest abstract and the lowest routine content. Rather, occupations such as production and craft or machine operators display the highest routine and the lowest service and abstract content.

In order to check whether there is a correlation between changes in the employment shares by occupations and task intensities, we regress (separately) changes in the share of employment by occupation (3-digit ISCO88 occupations) on the following measures of job contents: (i) abstract intensity, (ii) service intensity and (iii) routine intensity. In addition, following Goos et al. (2010, tables 6A, 6B and 7) and Autor and Dorn (2013), we also use a routinization index in a separate regression, which combines the previous three measures to create an index of routine task-intensity by occupation, which is defined as follows:

$$
\begin{array}{r}
\text { Routinization Index }=\log (\text { Routine Intensity })-\log (\text { Abstract Intensity }) \\
-\log (\text { Service Intensity }) .
\end{array}
$$

This index increases with the rise of routine intensity and declines with the rise of abstract and service intensity.

\footnotetext{
${ }^{2}$ In a more recent version of the Goos et al. (2010) paper, (see Goos et al. 2014), the authors use DOT measures instead of ONET ones and their results are almost the same.

${ }^{3}$ As a robustness check, we have used an alternative definition of routine-intensive jobs-only those whose content relate to Operation Monitoring and Operation and Control as Autor and Dorn (2013). The rest of job contents previously assigned as routine intensive by Goos et al. (2010) have been left aside (in their classification they also consider arm-hand steadiness, manual dexterity, finger dexterity and strength as routine job contents). Given that abstract, routine and service tasks are in relative terms, each of the measures has been redefined with respect to this alternative routine task measure. Results, although not reported and available upon request, are qualitatively identical to the ones found in the previous section, which suggests that the particular definition of routine-intensive tasks used in this paper is robust to alternative definitions of routine tasks used in other studies.
} 
Table 4 The effect of task intensities on changes in share of employment

\begin{tabular}{|c|c|c|c|}
\hline Independent variables & $\begin{array}{l}\text { (1) } \\
1997-2012\end{array}$ & $\begin{array}{l}(2) \\
1997-2007\end{array}$ & $\begin{array}{l}\text { (3) } \\
\text { Interacting effects }\end{array}$ \\
\hline Abstract intensity & $\begin{array}{l}-0.446 \\
(3.599)\end{array}$ & $\begin{array}{l}-2.551 \\
(2.851)\end{array}$ & $\begin{array}{l}-2.551 \\
(2.855)\end{array}$ \\
\hline Abstract intensity* dummy period (2012-2007) & & & $\begin{array}{l}3.148 \\
(3.757)\end{array}$ \\
\hline Routine intensity & $\begin{array}{l}-1.850 \\
(1.582)\end{array}$ & $\begin{array}{l}1.733 \\
(1.838)\end{array}$ & $\begin{array}{l}1.733 \\
(1.840)\end{array}$ \\
\hline Routine intensity* dummy period (2012-2007) & & & $\begin{array}{l}-5.780 * * \\
(2.586)\end{array}$ \\
\hline Service intensity & $\begin{array}{l}3.601 * * \\
(1.549)\end{array}$ & $\begin{array}{l}-1.743 \\
(2.381)\end{array}$ & $\begin{array}{l}-1.743 \\
(2.384)\end{array}$ \\
\hline Service intensity* dummy period (2012-2007) & & & $\begin{array}{l}8.590 * * * \\
(3.199)\end{array}$ \\
\hline Routinization index & $\begin{array}{l}0.293 \\
(0.296)\end{array}$ & $\begin{array}{l}-0.290 \\
(0.250)\end{array}$ & $\begin{array}{l}0.250 \\
(0.181)\end{array}$ \\
\hline Routinization index* dummy period (2012-2007) & & & $\begin{array}{l}-0.908 * * * \\
(0.334)\end{array}$ \\
\hline Observations & 70 & 86 & 156 \\
\hline
\end{tabular}

Dependent variable: change in share of employment (\% points)

Each coefficient corresponds to a separate OLS regression of the dependent variable on the control variables and a constant. Robust standard errors in parentheses. *** Significant at $1 \%$ level, ** significant at $5 \%$ level, * significant at $10 \%$ level. Number of observations is the number of occupations at ISCO88 3 digits level. These estimations include also period time dummies not reported here. All estimations are weighted by the weight of employment of each ISCO88 3 digits occupation in total employment

Table 4 presents the results of these estimations. The dependent variable is the change in the share of employment for each 3-digit ISCO88 occupation. We perform the estimations for the whole 15-year interval (1997-2012) and for the expansionary period (1997-2007). In the table, each coefficient is the result of a different OLS regression.

Results suggest that when using the Routinization Index as the regressor, there seems to be a negative impact of the index on the change in the share of employment; this is only significant for the recession period. When separating out the different task intensities, there is no significant correlation between the change in the share of employment and the "Abstract Intensity" of occupations. This is true when considering the whole 15-year interval jointly and for separate regressions in each period. On the other hand, "Routine Intensity" of occupations exhibits a clearly negative correlation with the change in the share of employment in the recession period. Finally, "Nonroutine Service Intensity" of occupations is positively and significantly correlated with the change in the share of employment. As before, the impact is particularly strong in the recession period. 
In this regard, the evidence above shows that during the expansion period there was polarization but the routinization theory does not hold. This is consistent with results in the previous section that showed that polarization mainly came via a reallocation of sectors. Indeed, it is likely that the big expansion of the Spanish labour force coupled with the construction boom delayed the rapid mechanization of certain routine occupations that occurred in other countries in the pre-crisis period. During these years, there was a notable increase in the share of low-skilled service occupations, such as personal services and workers in restaurants and hotels, but also in the share of low-skilled routine tasks such as cleaners of buildings. On the other hand, middle-skilled occupations with higher routine content, high-skilled service occupations (such as professional services) and occupations requiring abstract tasks (support in the financial sector and administration) also increased their share, although at a slower pace. During the recession, however, it appears that there is a clear decrease in the share of the routine occupations that could easily be mechanized (especially related to the construction bust and the industry decline). This is compensated by nonroutine services that move upward both low-paid (cleaners and personal services), and high-paid occupations (managers and professional services related to the service sectors as observed in Sect. 2). Instead, abstract tasks do not appear to increase their share during these 15 years.

\section{The effect of polarization for particular demographic groups}

This section introduces the link developed by Autor and Dorn (2009) with regards to the implication of the routinization theory for the change in the distribution of employment by age. Routinization implies the displacement of occupations which are intensive in routine tasks to occupations more intensive in non-routine (service or abstract) job contents. This non-neutral occupational change may change the age composition of occupations if there are different incentives and/or abilities of workers to enter/exit from rising/declining occupations at different stages of their life cycle. In their paper, they find that older workers, regardless of their skills, moved from routine to non-routine low-skilled jobs, whereas the displacement of young workers from routine jobs increased the share of both low-skilled non-routine jobs and high-skilled abstract jobs.

In this fourth section, we look specifically at employed workers and analyze how their age structure changes in rising and declining occupations. To this end, we follow Autor and Dorn (2009) and estimate changes in the age composition of workers in each occupation for each of the intervals considered before, according to the three different job contents, as well as the routinization index. We do this separately by gender.

However, before looking at changes in the age structure in declining and expanding occupations over time, the distribution of males and females across occupations by age at the initial period deserves some attention. As Table 1 indicates, by 1997, males were overrepresented in declining occupations with respect to females. The percentage of young females in managerial and service occupations (52\%) was much higher in 1997 than the corresponding percentage for males (29\%). Interestingly, although not reported, at a further occupational disaggregation - at a 2-digit level, young males 
in managerial/technical/professional occupations are overwhelmingly concentrated in jobs such as chemistry/physics technicians, engineers or professionals in finance and trade, all of which are very intensive in abstract contents. On the contrary, their female counterparts are concentrated in occupations such as teaching professionals, health professionals and administrative associate professionals, which require more service intensive tasks. With respect to non-managerial/technical/professional jobs, young males are scattered along production occupations, low-skilled occupations (especially industry and construction pawns), machine operators and, to a lesser extent, retail and sales. All these occupations use quite intensively routine tasks. However, young females in non-managerial/technical/professional occupations are distributed among clerical, retail and sales occupations and, to a lesser extent, among low-skilled service occupations - in particular in personal services. All these occupations primarily require service rather than abstract or routine tasks.

Given this, if we think about the impact of polarization on the reallocation of males and females across job contents, we would expect a change in the distribution of tasks of young males as a consequence of the decrease in the demand for routine tasks and an increase of abstract and service tasks. Something similar would occur with older males given that they are over represented in routine occupations related to machine operators and production and craft. However, for male workers between 31 and 45 years of age in 2012, cohort effects must be taken into account when interpreting the changes over time, since in 1997 these workers belonged to the youngest group. These cohort effects are not expected to be important when analyzing the group of male workers over 45 years old since the distribution of occupations in 1997 was similar to the one of middle aged workers. With respect to female reallocation, we would not expect much change in task performance as a result of the polarization process since by 1997 females seemed to be very concentrated in occupations which did not require routine intensive tasks. These issues must be taken into account when interpreting the results.

In order to account for the changes in the age composition, we use two different measures: the change in the mean age of each occupation and the change in the share of workers in each occupation (i) less than 30 years old, (ii) between 31 and 45 years old, and (iii) more than 45 years old.

According to the regressions where average age is the dependent variable (Table 5), we observe that workers in occupations with more abstract content are becoming younger, as average age decreases. This is particularly so in the expansionary period. For the recession period, given the mass layoffs of younger workers with temporary contracts, this phenomenon is not observed. However, the recession does not overcome the effect of the expansionary periods and, taking into account the whole cycle (19972012), workers in abstract occupations also become younger. By gender, it appears that only for males do we observe the decrease in average age in occupations with more abstract content over the whole cycle. There is also a decrease in average age of females in abstract occupations in the expansionary period, but this is reversed in the recession. For the overall period, no significant change in average age is found for females.

In occupations with more routine content, we observe a slight aging of workers, as average age seems to increase. The effects by sub-periods are only marginally 
significant, but when the whole 15 -year period is considered, we see a positive and stronger effect. When we disaggregate this by gender, we observe that if anything, the effect is driven by males, as we observed in occupations with higher abstract content.

In occupations with more non-routine service content, we observe a very similar feature to the one observed for occupations with abstract contents, but the effect seems to be smaller, namely, those workers in occupations with more service content are becoming younger. In this case, and differently from what happened with occupations with more abstract content, the effect is found to be significant in the recession period. As in the previous two cases, the effect is stronger for males. Indeed, for females the effect is not significant.

Regressions of the change in the share of workers by age provide more information on which age groups of workers are driving the previous results. Table 6 shows a process of rejuvenation motivated by an increase in the share of workers between 16 and 30 years old in occupations with more abstract and service contents. The former, which is especially intense, occurs during the expansion and the latter during the recession years. On the other hand, a clear aging effect is observed for occupations with more routine content. Again, there is no statistical effect for occupations with more abstract content.

Table 7 indicates that the share of middle-aged workers in routine tasks has increased substantially with the corresponding decrease in the share of occupations with both abstract and service content. This is consistent with the hypothesis that cohort effects are playing a role. This is not observed for females (indeed the point estimate corroborates a decrease in occupations of routine content).

Table 8 provides evidence for older workers. This group should not be affected as much by cohort effects. The evidence points towards a group of workers who are stuck in routine tasks. This could be the case because of high firing costs for those over 45 years old, as most of them hold indefinite contracts. Again, females do not show any relevant effect. If any, there is a slight increase of female incidence in occupations which require more service intensive contents throughout the crisis. We must look at these results with caution. Further research is needed to disentangle cohort effects properly from the reallocation of particular groups of workers.

To summarize, the observed polarization process over the 15-year period under analysis seems to have reallocated young male workers from occupations with more routine tasks to others with more abstract and non-routine service content. ${ }^{4}$ Young female workers who were already performing occupations with a high service content are not affected by this technological change. The fact that they are not working in abstract tasks is quite stunning and should be addressed carefully in further research. Instead, it looks like male workers over 30 are the ones who have stayed in the declining occupations more, especially those over 45. It is likely that this is the case because of the high severance payments that they have acquired during their lifetime.

\footnotetext{
4 We must not overcome the fact that young males have been hit by unemployment to a greater extent than their young female counterparts and than older males. Therefore, when we refer to reallocation of young males we restrict attention to employment shares, and to some extent ignore compositional changes due to exits from employment into unemployment.
} 


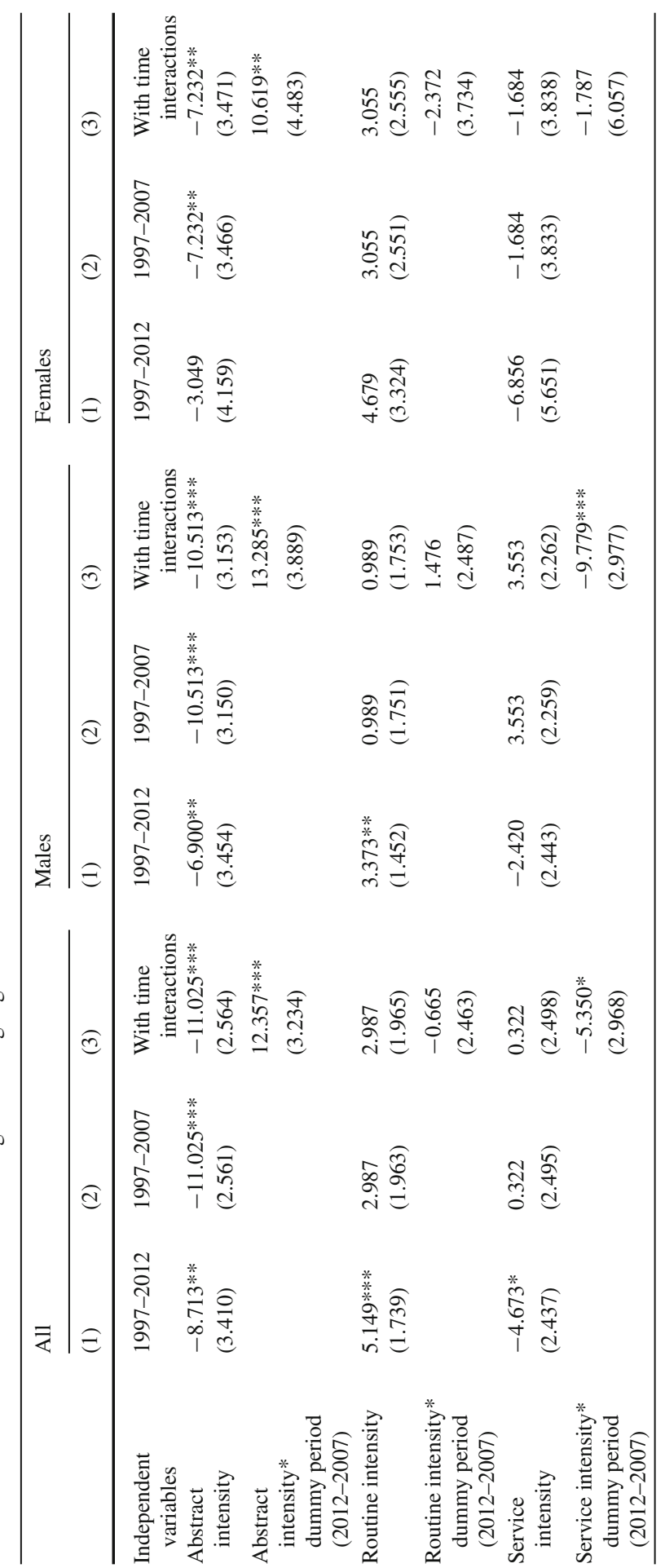




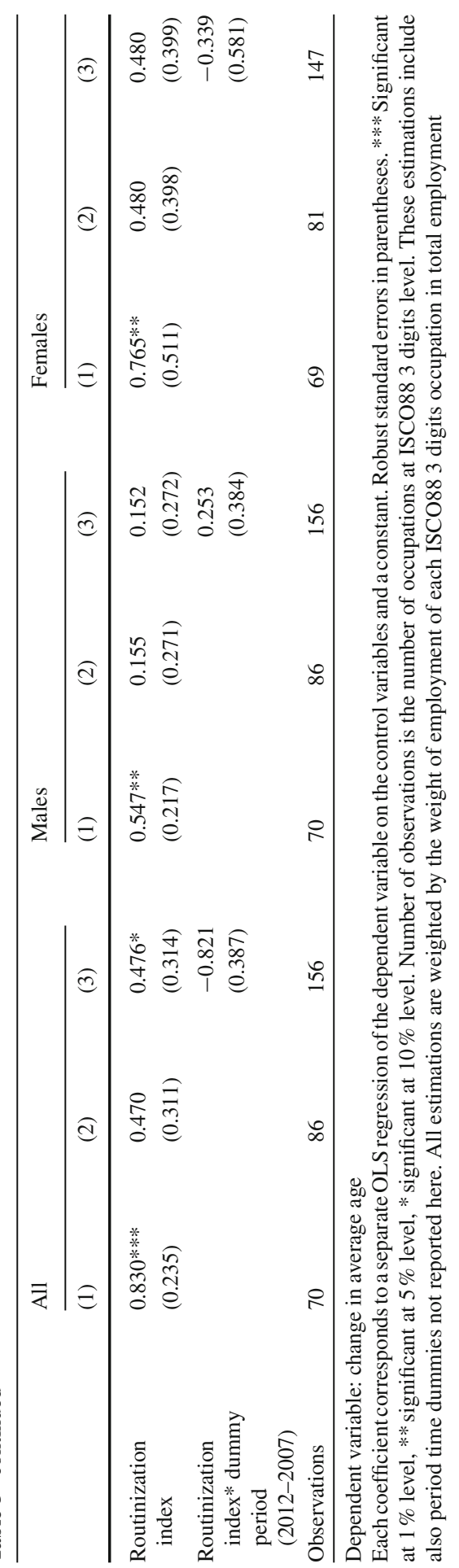




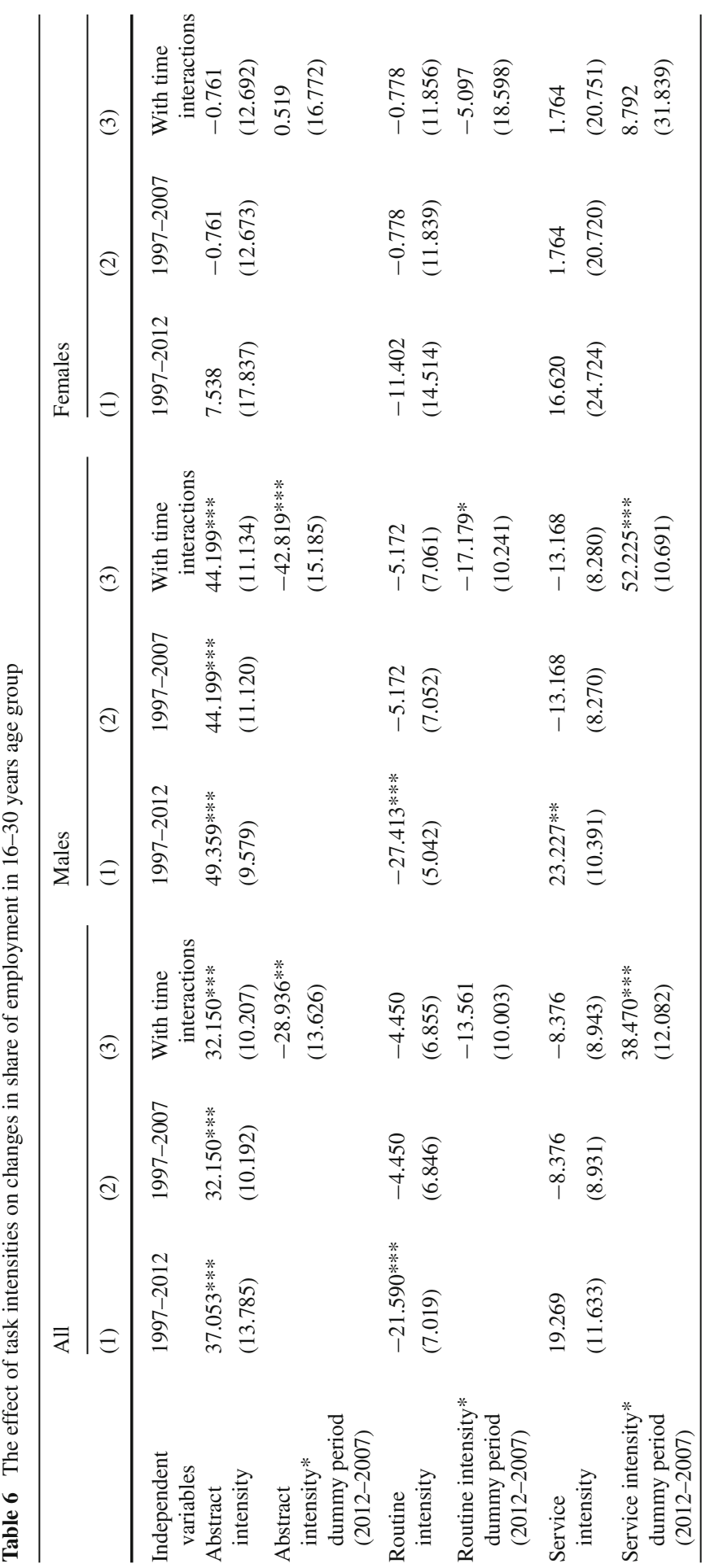




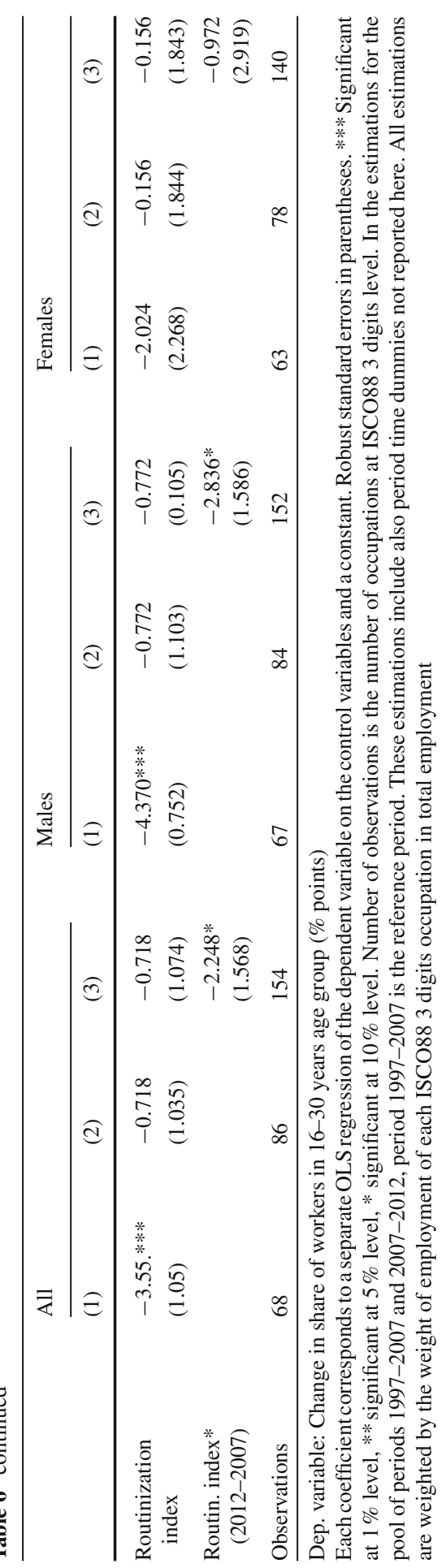




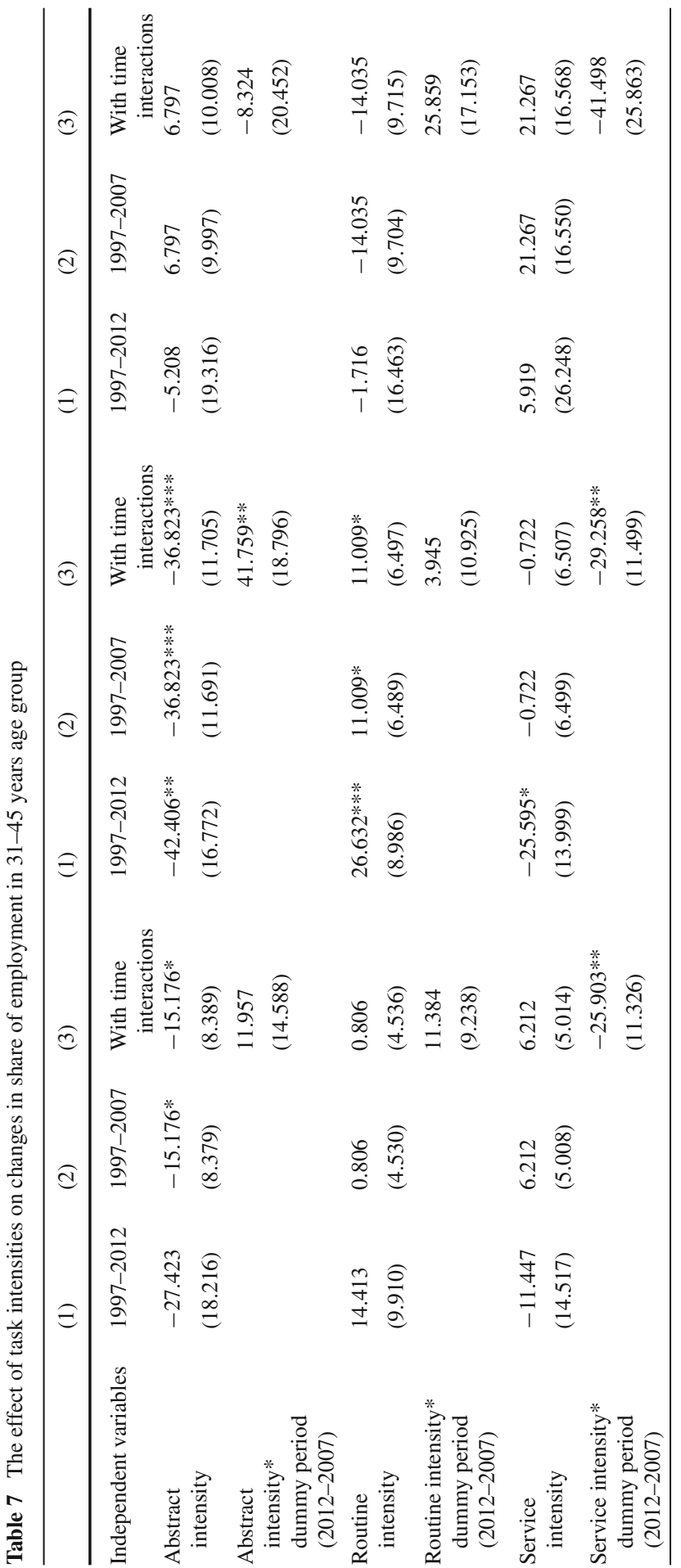




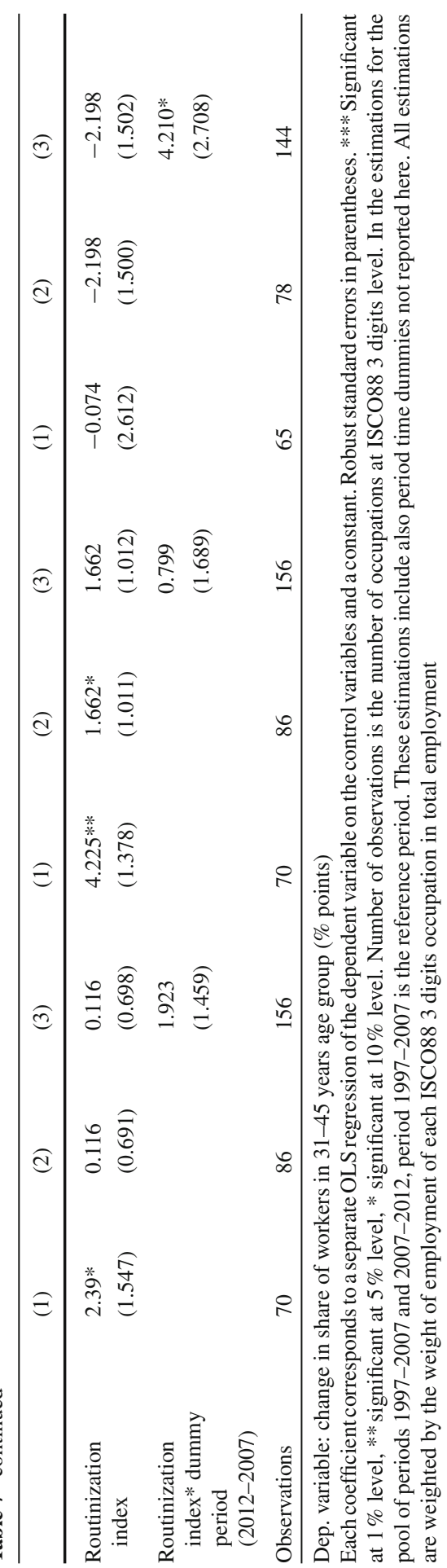




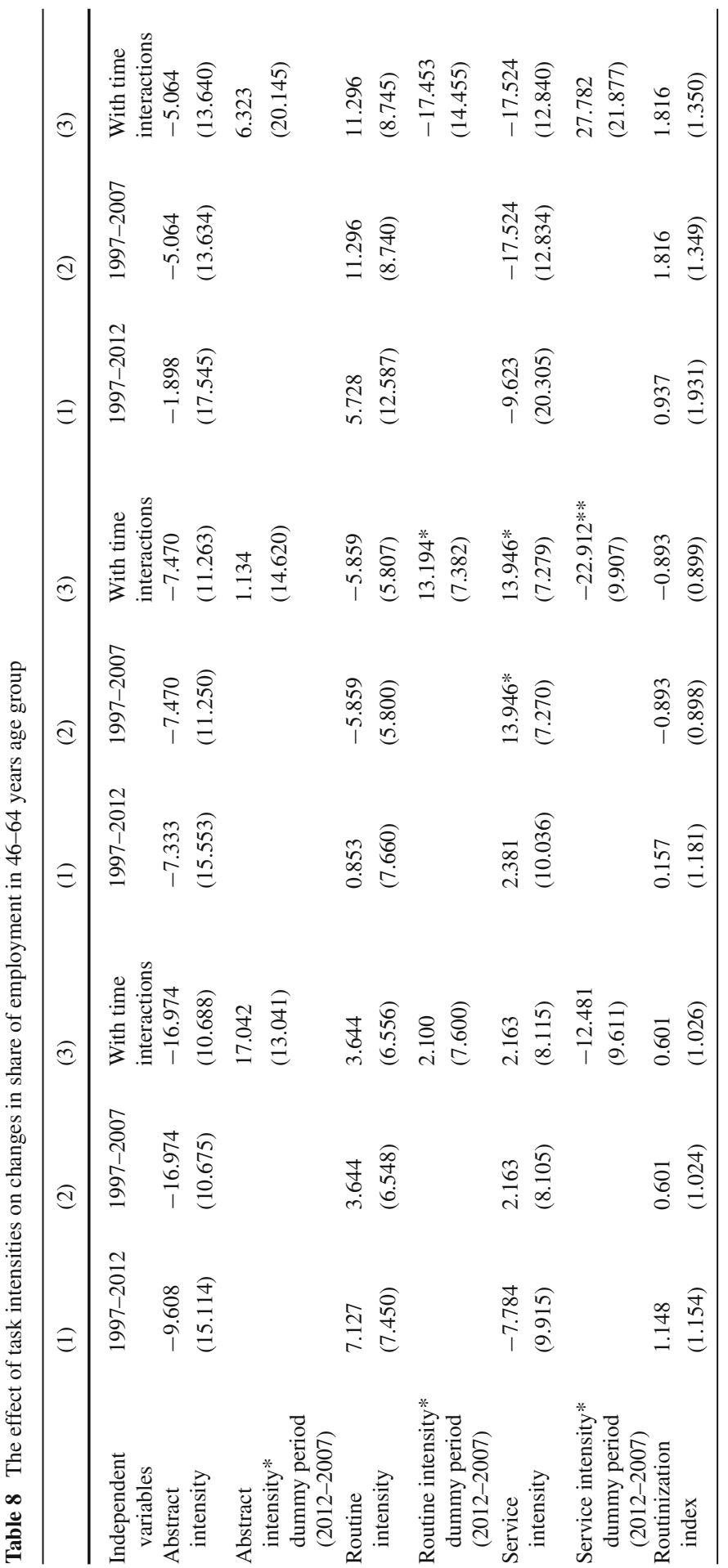




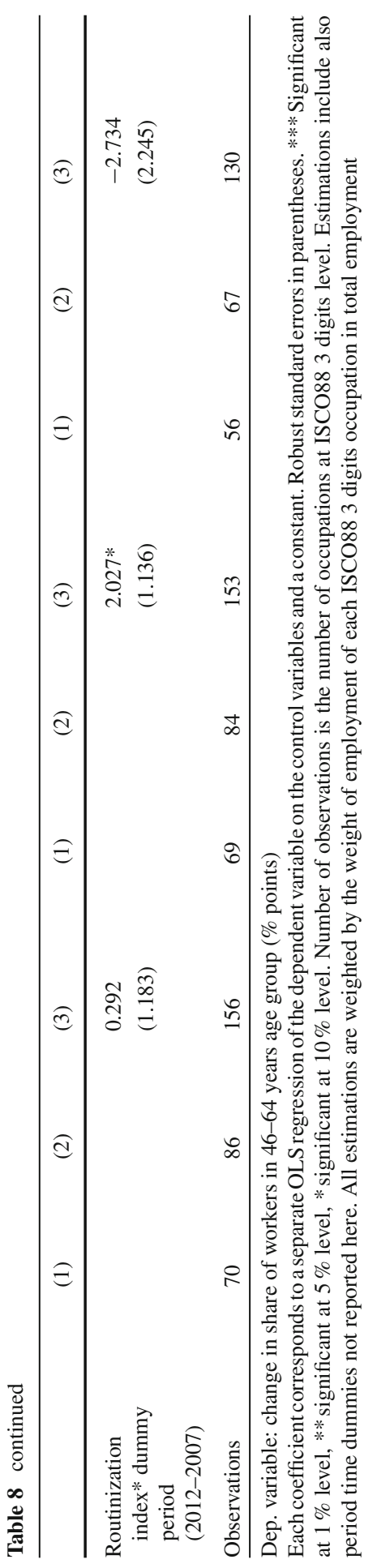




\section{Conclusions}

This article analyzes changes in the employment share of occupations in Spain for the period 1997-2012 and the way particular sociodemographic groups adapt to them. We analyzed a whole cycle in order to find structural factors underlying such changes but we addressed the extent to which these occupational changes differed during the expansion and the recession years.

On the first hand, we addressed whether Spanish occupations experienced a process of polarization. That is, whether those occupations at the low and high end of the wage distribution expanded relative to the rest. We found clear evidence of polarization, both for the expansionary and for the recession period as well as for the whole 15year interval. Nevertheless, there is a distinct pattern of polarization between 1997 and 2007 and the recession period. During the first 10 years and coinciding with the expansionary period, low-paying occupations expanded in employment terms relative to average-paying occupations but also with respect to high-paying occupations.

Next, we tested whether these changes follow from hypotheses such as changes in the composition of the labour supply or changes in sector allocation. We showed that changes in the composition of the labour force would have increased the share of occupations placed at the upper end of the wage distribution instead of the observed polarization process. During the recession, compositional changes, if anything, might have contributed even more to the expansion of occupations at the upper part of the wage distribution. Therefore, supply side changes cannot explain the increase in the share of occupations at the low end of the wage distribution. Regarding sector reallocation, we performed a shift share analysis of the changes to conclude that overall changes across sectors, potentially due to the housing boom, might have partially contributed to explain the polarization process in Spain especially during the period of expansion (1997-2007). Nevertheless, when considering the whole cycle (19972012), within sector changes are the major factor behind the observed occupational changes.

We then explored whether polarization arises as a result of a decrease in occupations which are intensive in routine contents. In this regard, we found that the observed polarization is indeed consistent with a decrease in occupations intensive in routine content and an increase in those intensive in non-routine services which are found both at the low and high end of the wage distribution. Instead, occupations with higher abstract tasks do not appear to have expanded during these 15 years.

Needless to say, these changes in the employment composition are not homogeneous across different sociodemographic groups. The paper finds that the observed decrease in routine occupations over the 15 years under analysis seems to have affected males more strongly than females as a result of their higher concentration in occupations which are intensive in routine tasks. Indeed, for male workers, the share of the unemployed in the population has increased notably, regardless of the age group. Young male workers decrease their share in occupations with more routine tasks and increase it in occupations with more abstract and, in particular, with more non-routine service content. Rather, male workers over 30 years of age tend to stay in the declining occupations. Females, given that they were not allocated to routine tasks during the 
expansionary period, are not affected as much by these changes, probably due to the fact that they were already more specialized in jobs with high service content.

Open Access This article is distributed under the terms of the Creative Commons Attribution License which permits any use, distribution, and reproduction in any medium, provided the original author(s) and the source are credited.

\section{Appendix: Occupations and measures of job contents}

To match occupations with particular job contents we rely on information on job task requirements assembled by Peri and Sparber (2009) for the US, Goos et al. (2010) for different European countries, and Amuedo and De la Rica (2011) for Spain, among others. The starting point is to merge data on job contents (or task requirements) based on the US Department of Labor's ONet survey ${ }^{5}$ with Census occupation classifications to examine task specialization patterns of workers. ONet is a primary source of occupational information providing data on key attributes and characteristics of occupations. It replaces the Dictionary of Occupational Titles (DOT), which was used for earlier research, prominently by Autor et al. (2003). ONet data is collected for 812 occupations based on the 2000 Standard Occupational Code (SOC).

Through the development of careful crosswalks with the International Standard Classification of Occupations from 1988 at 3-digits level (ISCO88), ONet data has been increasingly used by a large number of researchers and institutions outside the United States. ${ }^{6}$ We merge the ONet job skill data with the Spanish Labor Force Survey with occupations disaggregated at 3 -digits level. ${ }^{7}$ Like previous authors using the ONet dataset with European data, ${ }^{8}$ we do so under the assumption that the occupations in the US and in Spain being examined herein are not that different with regards to the specified job contents.

ONet consists of around 100 variables related to the intensity of different job activities and abilities for each occupation. The original values range from 1 (very low intensity) to 5 (very high intensity). For comparability reasons, we use exactly the same variables as in Goos et al. (2010) to construct the job content measures we use for the analysis. Specifically, we make use of 96 of these variables and each of them is categorized into one of the following job contents: Abstract, Routine and non-Routine Service.

To give a broad idea of what type of content is included in each of the three measures, "Abstract Intensity" measures the extent to which each occupation entails activities such as: active learning, learning strategies, management of personal resources, man-

\footnotetext{
${ }^{5}$ For the rest of the section on polarization, we will use the 3-digit ISCO-88 classification.

${ }^{6}$ In general, statistical significance of the regressions of females is low compared to that of males, but the signs coincide.

7 They use version 11.0 of the survey, available at: http://www.onetcenter.org/.

8 The ONet rates the importance of 99 job characteristics, including employee skills and employee activities - to which we refer to as task requirements or tasks in this paper-in each occupation in the Standard Occupation Classification (SOC). This information is continually updated by surveying a broad range of workers from each occupation in the US.
} 
agement of material resources, deductive reasoning, speech clarity, complex problem solving, etc. "Routine Intensity" measures the extent to which each occupations entails activities such as: operation monitoring, operation and control, quality control analysis, arm-hand steadiness, manual and finger dexterity. Finally, "Non-Routine Service Intensity" measures the extent to which each occupation entails activities such as: assisting and caring for others, establishing and maintaining interpersonal relationships, selling and influencing others, active listening. The exact definition of each job content is detailed in Goos et al. (2010, Table C1 (pp: 73)).

In order to construct the final measure of intensity in each of the described job contents, we must realize that the standard deviation varies to a great extent depending on the skill under consideration. This problem is also detected and accounted for by Peri and Sparber (2009), who tackle it by transforming the ONet job skill data to reflect the relative importance of each skill among all US workers in 2000. Like them, we transform the original job content data to reflect the relative importance of each skill among all workers in Spain during the time period under examination.

As in Peri and Sparber (2009), the final measures of Abstract, Routine and NonRoutine Service Job Contents are the weighted averages of the intensity of the activities included under each of the three measures. ${ }^{9}$ In addition, given that our aim is to provide relative measures of intensity of abstract, routine and non-routine service job contents for each occupation, we normalize the intensity of each of these three job contents within occupations so that the sum of the intensities of the three of them is 1 .

Table 2 displays the Abstract, Routine and Non-Routine Service Job Content values for each of the eight big occupational groups. This allows us to gauge the suitability of the ONet data in describing the distinct job content of the main Spanish occupational categories. As expected, high skill occupations, such as technical and professional occupations display a higher value of Abstract Content and a smaller value of Routine Content. The contrary is observed for low skill occupations, such as machine assemblers and low-qualified service occupations. With regards to the intensity of non-routine service jobs, higher values are observed for occupations at the two tails of the skill distribution.

\section{References}

Acemoglu D, Autor DH (2011) Skills, tasks and technologies: implications for employment and earnings. In: Ashenfelter O, Card DE (eds) Handbook of labor economics, vol 4. Amsterdam, Elsevier

Amuedo C, De la Rica S (2011) Complements or substitutes: task specialization by gender and nativity in Spain. Labour Econ 18(5):697-707

Autor D (2013) The "task approach" to labor markets: an overview. J Labour Mark Res 1-15

Autor D, Dorn D (2009) This job is "Getting Old": measuring changes in job opportunities using occupational age structure. Am Econ Rev Pap Proc 99(2):45-51

Autor D, Dorn D (2013) The growth of low-skill service jobs and the polarization of the U.S. Labor Market. Am Econ Rev 103(5):1553-1597

Autor D, Levy F, Murnane R (2003) The skill content of recent technological change: an empirical investigation. Q J Econ 118(4):1279-1333

Autor D, Katz L, Kearney M(2006) The polarization of the U.S. Labor Market. Am Econ Rev 96(2):189-194

\footnotetext{
9 See http://www.onetcenter.org/dl_files/paw/Products_at_Work.pdf for a summary of its many applications outside the US.
} 
Carrasco R, Jimeno JF, Ortega C (2012) Accounting for changes in the Spanish wage distribution: the role of employment composition effects. Banco de España Working papers 1120

Gavilán Á (2012) Wage inequality, segregation by skill and the price of capital in an assignment model. Eur Econ Rev 56(1):116-137

Goos M, Manning A (2007) Lousy and lovely jobs: the rising polarization of work in Britain. Rev Econ Stat 89(1):118-133

Goos M, Manning A, Salomons A (2009) Job polarization in Europe. Am Econ Rev Pap Proc 99(2):58-63

Goos M, Manning A, Salomons A (2010) Explaining job polarization in Europe: the roles of technology, globalization and institutions. CEP Discussion Paper No 1026, November

Goos M, Manning A, Salomon A (2014) Explaining job polarization: routine-biased technological change and offshoring. Am Econ Rev (forthcoming)

Izquierdo M, Lacuesta A (2012) The contribution of changes in employment composition and relative returns to the evolution of wage inequality: the case of Spain. J Popul Econ 25(2):511-543

Jamovich N, Siu HE (2012) The trend is the cycle: job polarization and jobless recoveries. NBER Working Paper 18334

Ljungqvist L, Sargent T (1998) The European unemployment dilemma. J Political Econ 106(3):514-550

Peri G, Sparber C (2009) Task specialization, immigration, and wages. Am Econ J Appl Econ 1(3):135-169

Wasmer E (2006) Interpreting Europe-US labor market differences: the specificity of human capital investments. Am Econ Rev 96(3):811-831 